\title{
Mapping rehabilitation resources for head injury
}

\author{
J D Pickard FRCS FMedSci ${ }^{1}$ \\ H M Seeley MSc BA $^{1} \quad$ S Kirker MD FRCPI $\left.\right|^{2}$ \\ C Maimaris FRCS FSAEM ${ }^{3}$ \\ K McGlashan MBBS MRCP4 \\ E Roels $M^{4} \quad$ R Greenwood MD FRCP ${ }^{5}$ \\ C Steward BSc MBA 6 \\ P J Hutchinson PhD FRCS ${ }^{1}$ \\ G Carroll MSc FFPHM 6
}

J R Soc Med 2004;97:384-389

\section{SUMMARY}

Several reports have pointed to the unevenness in the UK of services for rehabilitation after head injury. A study was conducted in the Eastern Region of England to define the key stages in recovery and rehabilitation, by an iterative process of questionnaire, interview and consensus conference. Findings were translated into a draft set of maps showing current availability of services which were revised after feedback. Working groups then developed a set of definitions and classification codes for each stage of rehabilitation which were likewise disseminated for feedback. The maps were then redrafted to correspond with the definitions together with a flowchart of potential head injury rehabilitation services. The definitions were piloted at a regional neurosurgery unit and a rehabilitation hospital. Core services for neurorehabilitation region-wide were found to be variable and uncoordinated with fragmented and inequitable allocation of resources. The definitions and mapping system that emerged from this study should facilitate the design of care pathways for patients and identify gaps in the services.

\section{INTRODUCTION}

Much effort is being devoted to creating service frameworks, guidelines and standards for the care of the 500000 patients who sustain a head injury each year in the UK.1,2 Four years ago the Eastern Region Head Injury Group (ERHIG) was established jointly by the Academic Neurosurgery Unit at Addenbrooke's Hospital and the Regional Services Commissioning Group in response to national reports on the management of head injury. ${ }^{3-5} \mathrm{~A}$ further impetus to the group's work came from the recommendations of a Parliamentary select committee. ${ }^{6}$ Phase I of ERHIG's work included a systematic assessment of the pattern of acute care and resources for head injury in twenty district general hospitals and the two neurosurgery units in the six counties of the Eastern Region. This survey indicated that core services were patchily distributed and needed to be better coordinated, with clearly defined responsibilities and care pathways. ${ }^{7}$ Progress to this end has been hampered by the absence of a simple overview of the rehabilitation process that describes the individual's needs that can be readily understood by all concerned-patients, families, carers, service providers,

${ }^{1}$ Academic Neurosurgery, ${ }^{2}$ Lewin Stroke \& Rehabilitation Unit, and ${ }^{3}$ Accident \& Emergency Department, Addenbrooke's Hospital, Cambridge; ${ }^{4}$ District Rehabilitation Centre, Colman Hospital, Norwich; ${ }^{5}$ Regional Neurological Rehabilitation Unit, Homerton Hospital, London; ${ }^{6}$ East of England Specialised Commissioning Group, Cambridge, UK

Correspondence to: Professor J D Pickard, Academic Neurosurgery, Box 167, Addenbrooke's Hospital, Hills Road, Cambridge CB2 2QQ, UK planners and commissioners. In phase II we have addressed rehabilitation issues for the whole spectrum of head-injured patients. Here we describe the development of a set of definitions and a system for mapping the rehabilitation process that will help identify gaps in services, set criteria for movement between sectors and allow an individual's progress to be audited.

\section{METHODS}

\section{Mapping the geographical distribution of rehabilitation services}

A questionnaire survey, supplemented by service visits, was conducted to ascertain the extent of the current head-injury rehabilitation services in the Eastern Region. The findings of the questionnaire survey were translated into a series of maps showing the currently available services as related to each stage of rehabilitation for acute and community support after head injuries of different severity. The first draft of the maps was disseminated for feedback and debate at a multidisciplinary review meeting with external advisers.

\section{Definitions and classification of rehabilitation services}

Working groups for acute, early and late rehabilitation after head injury were formed and a set of definitions and classification of rehabilitation was collaboratively developed. Each stage was given a clearly defined classification code, a patient description, location(s) for that stage to 
Code Title and description
Sites

Acute A\&E observation ward requiring $24-48 \mathrm{~h}$ observation prior to community rehabilitation, with low probability of acute neurological deterioration

10

Supportive rehab-Medically unstable, requiring neurosurgical or clinical care

20 Supportive rehab-Medically unstable, not Acute hospital requiring neurosurgical or critical care

30 Rapid access rehab-Medically stable, not Acute hospital (necessarily) able to actively participate due to amnesia, confusion, rejection, low response or awareness

40 Active participation inpatient rehabMedically stable, able to actively participate with, and benefit from, therapy

50 Behavioural rehab-Medically stable, but prolonged confusion, amnesia or behavioural difficulties, requiring specialist behavioural management, intensive supervision and secure environment

60 Slow-stream rehab-Medically stable, but Community hospital or specialist low awareness or response persists beyond inpatient unit

e.g. 3 weeks after sedation withdrawn and medically stable. Able to benefit from medical and physical therapy to prevent complications and support recovery

70 Community rehab-Medically stable, able to actively participate with, and benefit from, therapy. Will include spectrum of initial severity of injury with a small minority derived from code 05 category

80 Intensive cognitive rehab-Medically stable, Domiciliary or day hospital independently mobile, primarily cognitive impairments likely to benefit from intensive neuropsychological therapy

90 Specialist vocational rehab-Medically stable, living in community, aiming to enter/ return to employment

100 Maintenance-Medically stable, but permanent disability

110 Social, patient and carer support-Carer support from initial injury, patient support when able to communicate
Acute or community hospital

Specialist inpatient unit

Domiciliary or day hospital

Domiciliary or residential

Domiciliary, residential or nursing home, respite unit

All sites

\section{Description of rehabilitation input}

Assessment and observation-education, emotional and social support. Planned discharge home or moves to code 30 at $48 \mathrm{~h}$

Identifying and addressing early rehab goals before medically stable and transfer of care to rehab team

As for code 10

Needs inpatient care due to physical dependency and requires continuous clinical assessment to facilitate optimal timing for rehab input and detect clinical deterioration. Immediate early rehab delivered, and judgment made on timing/ appropriateness of referral to next rehab sector

Needs inpatient care due to physical dependency, or need for specialist therapy equipment, safe environment, supervision or intensity of therapy which cannot be provided in community

Specialist behavioural management, including high staff/patient ratio to ensure intensive supervision and secure environment; access to neuropsychology and neuropsychiatry

Assessment/active rehabilitation phase which needs to be distinguished from long-term care, although planning of care increasingly important aim after e.g. 6 months. Patients may go to active participation unit if sufficient improvement

Interdisciplinary coordinated management therapy aimed at community reintegration/ inclusion by enhancing independence and assisting return to work/education. In collaboration with social services, voluntary and statutory services. Includes treatment of patients in residential care or with live-in carers

Aiming to return to work, studies or independent community life

Aiming for return to work where this is influenced by physical or cognitive problems, or needs residential placement

Prevent deterioration of physical, emotional and behavioural condition, and long-term management of seating, pressure, spasticity etc. Developing social skills, stamina, confidence, attention and leisure pursuits, sorting out benefits, day supervision, respite care. Specific attention paid to: community involvement and integration (further education etc); personal social development; structured daytime activity; family support and outreach 
take place (including examples), necessary level of rehabilitation input and indications for moving between sectors.

These were disseminated to key personnel throughout the Eastern Region for comment and agreement. The maps were then redrafted to correspond with the agreed rehabilitation codes and definitions, together with a flowchart of potential head injury rehabilitation services.

\section{Piloting the definitions}

The definitions and classification codes were piloted prospectively at Addenbrooke's Hospital Neuroscience Critical Care Unit and in the neurosurgical wards immediately before discharge from neurosurgical care, and retrospectively at the Colman Hospital in Norwich (inpatient rehabilitation) for the post-acute stages, to test for adequacy, appropriateness and effectiveness.

At Addenbrooke's the pilot study was conducted over six months from April to October 2002. A weekly headinjury ward round was jointly conducted by neurosurgery and rehabilitation consultants to assess the inpatient rehabilitation needs of head-injured patients admitted to and discharged from the neurosciences critical care unit and the neurosurgical wards. Data on each patient, including postcode and severity of injury, were collected by means of a proforma and an Access database.

The study at the Colman Hospital covered twelve months from April 2002 to April 2003, the same information being collected.

\section{RESULTS}

The iterative process of consultation yielded consensus definitions for each component of the rehabilitation service pathway for head-injured adults (Table 1). Codification of the resultant definitions then permitted construction of a flow chart (Figure 1). These definitions for each step in the care pathway allowed maps to be drawn of the geographical provision of each component throughout the Eastern Region (Figure 2). Maps 3, 5 and 6 starkly illustrate the gaps in service provision. The survey revealed important deficiencies in the care pathways and continuity of care at both acute and late stages of rehabilitation as well as for

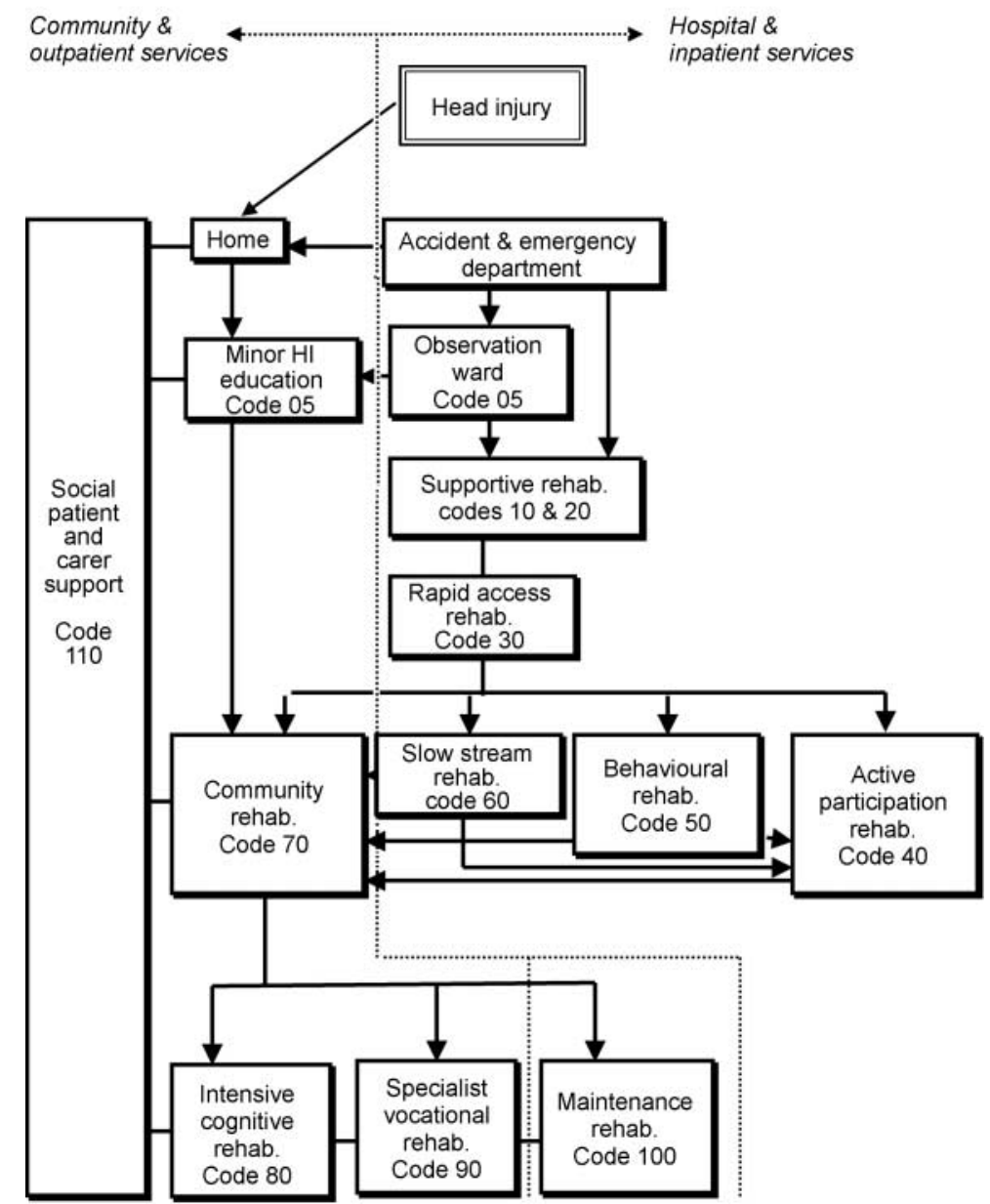




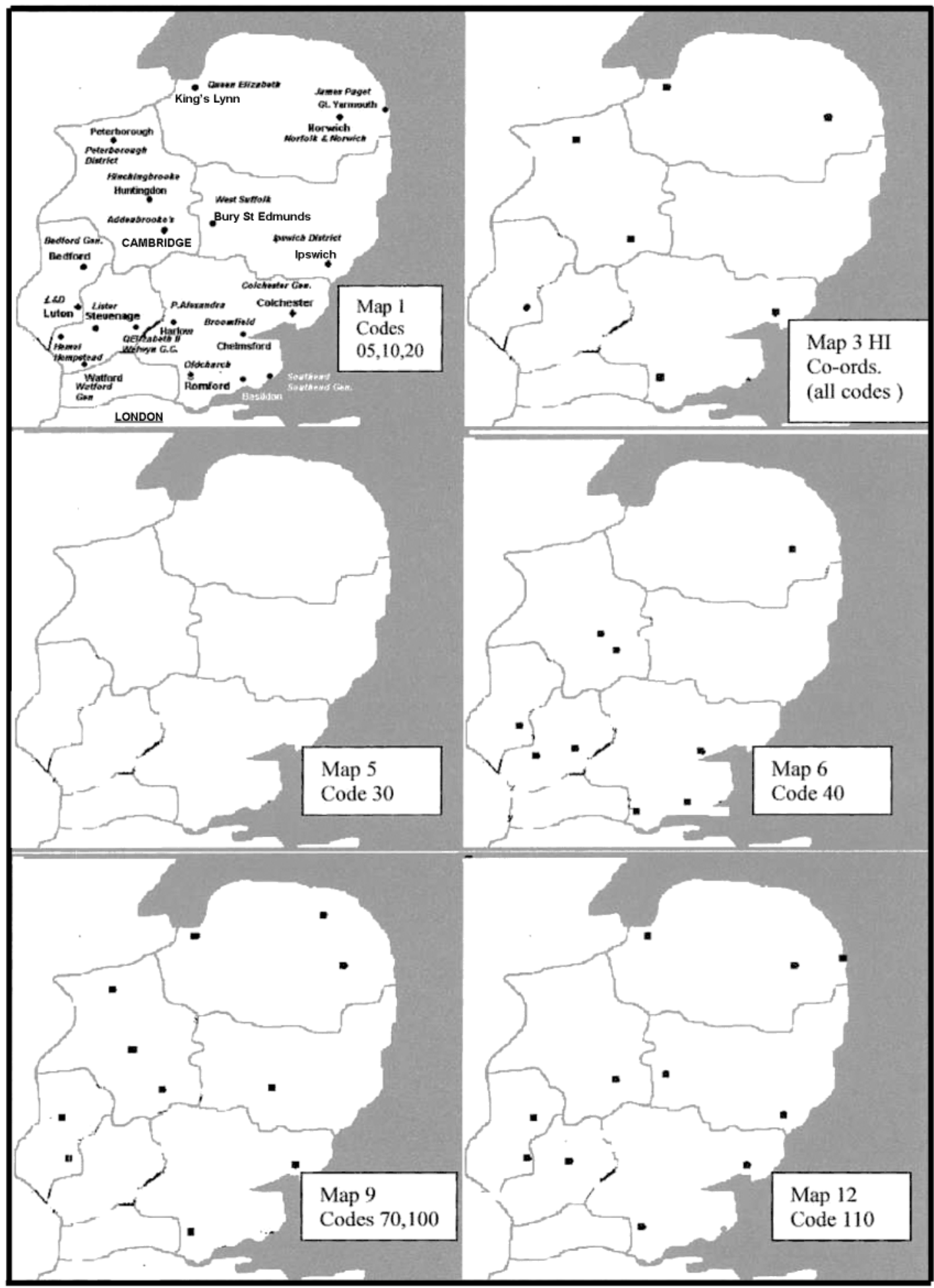

Figure 2 Mapping of neurorehabilitation services, Eastern Region

specific programme categories - for example, patients with severe behavioural disorders. Distribution and allocation of resources were found to be fragmented and unevendeficiencies that appeared to be compounded by lack of an overall structure and of coordination between acute and community providers.
In the six-month study at Addenbrooke's, 130 patients with traumatic brain injury were admitted, of whom 25 died. The rehabilitation needs of the remaining 105 patients were assessed prospectively according to the new coding system and Table 2 lists the categories of rehabilitation relevant to the 75 survivors. 37 patients were transferred to 
Table 2 Rehabilitation codes at discharge from neurosurgical care for 105 head-injured patients

\begin{tabular}{lcll}
\hline Code & $\begin{array}{l}\text { No. of } \\
\text { patients }\end{array}$ & $\begin{array}{l}\text { Patients } \\
\text { misplaced }\end{array}$ & $\begin{array}{l}\text { Discharge delayed } \\
\text { through lack of facility }\end{array}$ \\
\hline 05 & 30 & 1 & 0 \\
10 & 9 & 0 & 2 \\
20 & 28 & 0 & 4 \\
30 & 9 & 5 & 7 \\
40 & 10 & 1 & 2 \\
50 & 0 & 0 & 0 \\
60 & 3 & 0 & 1 \\
70 & 16 & 0 & 0 \\
Total & 105 & 7 & 16 \\
\hline
\end{tabular}

There were no patients for categories $80,90,100$ or 110

inappropriate acute wards despite being ready for a rapidaccess unit (which is not available in the Region). 3 patients should have been transferred to a slow-stream rehabilitation unit.

14 patients with traumatic brain injury were admitted to the rehabilitation unit in Norwich, and use of the codes again highlighted delays in discharge and follow-up and inappropriate provision of care. Of these 14 patients, 8 had been looked after on non-specialist wards.

The codes proved easy to use and no patient fell outside the definitions.

\section{DISCUSSION}

The principles underlying the rehabilitation needs of the victims of head injury have been known since the Second World War, when experience with military casualties led to great advances. ${ }^{8,9}$ The UK can boast neurorehabilitation centres of international repute, but in general head injury rehabilitation has not matched the success of the supraregional system of spinal cord injury centres. This deficiency has been deplored by numerous official reports and editorials from 1945 onwards. Part of the difficulty results from the much greater number of head-injured patients and the wide range of their disabilities - physical, behavioural and cognitive. Moreover, an argument for diversion of resources demands clear evidence that rehabilitation is effective. ${ }^{10}$ In the opinion of ERHIG, head-injury rehabilitation is neither intractable nor unaffordable.

The definitions and maps developed in this exercise are readily understood and facilitate the design of care pathways for individual patients, service planning and audit. Our flow chart is an elaboration of the Slinky model of the phases of rehabilitation, which emphasizes the seamless integration of the different stages of care, but the reality of the process is much more complex and three-dimensional than the Slinky model suggests, as emphasized by Turner-Stokes in the new National Guidelines for Rehabilitation following Acquired Brain Injury. ${ }^{11}$ The process of agreeing definitions was sometimes tortuous. There was considerable variation of opinion over what constitutes acute, post-acute and early rehabilitation, when it should start and what criteria should be used to decide when it has been completed. Numerical codes proved less contentious than titles.

The Eastern Region is not alone in the patchy nature of its provision for rehabilitation for the head-injured.6,12 The process described in this paper offers a way to identify blocks and delays in the care pathways and any shortfalls in resources. In subsequent work we aim to determine the likely numerical and fiscal demands on each component of the pathway and derive costings based on outcome, along the lines already achieved for regional acute neurosurgical care. $^{13}$

Finally, the model should prove helpful to patients and their families, as a means to illustrate the long process that may await them and in which they will have a key part to play. ${ }^{14,15}$

Acknowledgments H M Seeley was partly funded by the Eastern Region Specialised Commissioning Group; P J Hutchinson is funded by an Academy of Medical Sciences/ Health Foundation Senior Surgical Scientist Fellowship.

Members of the Rehabilitation Subpanel were: N Burchett (Queen Elizabeth Hospital, King's Lynn), M Cooper (Headway, Colchester), P Durrant (Headway, Cambridge), J Evans (Oliver Zangwill Centre, Ely), M Garner (Sue Ryder Home, Ely), A Gent (BIS UK), R Greenwood (Homerton Hospital, London), S Kirker (Lewin Rehabilitation Unit, Cambridge), K McGlashan (Colman Hospital, Norwich), C Noble (Neurorehabilitation Team, Peterborough District Hospital), P Osuwu (Peterborough District Hospital), H Seeley (Neurosurgery, Addenbrooke's, Cambridge), A Tyerman (Camborne Centre, Aylesbury), D Wade (Rivermead Rehabilitation Centre, Oxford), N Williams (OT BI Outreach/Lewin Unit, Cambridge).

\section{REFERENCES}

1 Thornhill S, Teasdale GM, Murray GD, McEwen J, Roy CW, Penny KI. Disability in young people and adults one year after head injury: prospective cohort study. BMJ 2000;320:1631-5

2 Tennant A. The epidemiology of head injury. In: Chamberlain MA, Neumann V, Tennant A, eds. Traumatic Brain Injury Rehabilitation. London: Chapman \& Hall, 1995

3 British Society of Rehabilitation Medicine. Rehabilitation after Traumatic Brain Injury. London: Royal College of Physicians, 1998:8

4 Royal College of Surgeons of England. Report of the Working Party on the Management of Patients with Head Injuries. London: RCS, 1999 
5 Society of British Neurosurgeons. Safe Neurosurgery 2000. London: SBNS, 2000

6 House of Commons Select Committee on Health. Third Report: Head Injury: Rehabilitation, 2001. London: Stationery Office, 2001

7 Seeley H, Maimaris, C, Carroll G, Kellerman J, Pickard J. Implementing the Galasko Report on the management of head injuries: the Eastern Region approach. Emerg Med J 2001;18:358-65

8 Russell WR. Rehabilitation after gunshot wounds of the brain. Br J Surg War Surg 1947; (War Surg. Suppl. No. 1)252-5

9 London PS. Some observations on the course of events after severe injury of the head. Ann R Coll Surg Engl 1967;41:460-79

10 McMillan TM, Greenwood R. Head injury rehabilitation. In: Greenwood R, et al., eds. Handbook of Neurological Rehabilitation (3rd edn, Chapt 5). Hove: Psychology Press, 2003:465-85
11 Turner-Stokes L, ed. Rehabilitation Following Acquired Brain Injury. National Clinical Guidelines. London: Royal College of Physicians \& British Society of Rehabilitation Medicine, 2003

12 Meek C. What happens next? Health Which October 2002: 22-5

13 Pickard JD, Bailey S, Sanderson H, Rees M, Garfield JS. Steps towards cost benefit analysis of regional neurosurgical care. BMJ 1990;301:629-35

14 Barnes MP. Organisation of neurological rehabilitation services. In: Greenwood R, et al., eds. Handbook of Neurological Rehabilitation, 2nd edn, Chapt 3. Hove: Psychology Press, 2003:29-40

15 Olivier MA. A different viewpoint-who needs rehabilitating? In: Greenwood R, et al., eds. Handbook of Neurological Rehabilitation, 2nd edn, Hove: Psychology Press, 2003:38-9 